\title{
Small-scale drivers on plant and ant diversity in a grassland habitat through a multifaceted approach
}

\author{
Michele Mugnai ${ }^{\text {Corresp., } 1}$, Clara Frasconi Wendt ${ }^{1}$, Paride Balzani ${ }^{1,2}$, Giulio Ferretti ${ }^{1}$, Matteo Dal Cin ${ }^{1}$, Alberto \\ Masoni $^{1}{ }^{1}$, Filippo Frizzi ${ }^{1}$, Giacomo Santini ${ }^{1}$, Daniele Viciani ${ }^{1}$, Bruno Foggi ${ }^{1}$, Lorenzo Lazzaro ${ }^{1}$ \\ ${ }^{1}$ Department of Biology, University of Florence, Firenze, Italy \\ 2 Faculty of Fisheries and Protection of Waters, South Bohemian Research Center of Aquaculture and Biodiversity of Hydrocenoses, University of South \\ Bohemia, Vodňany, Czech Republic \\ Corresponding Author: Michele Mugnai \\ Email address: michele.mugnai@unifi.it
}

Semi-natural grasslands are characterized by high biodiversity and require multifaceted approaches to monitor their biodiversity. Moreover, grasslands comprise a multitude of microhabitats, making the scale of investigation of fundamental importance. Despite their wide distribution, grasslands are highly threatened and are considered of high conservation priority by Directive no. 92/43/EEC. Here, we investigate the effects of smallscale ecological differences between two ecosites present within the EU habitat of Community Interest of semi-natural dry grasslands on calcareous substrates (6210 according to Dir. 92/43/EEC) occurring on a Mediterranean mountain. We measured taxonomic and functional diversity of plant and ant communities, evaluating the differences among the two ecosites, how these differences are influenced by the environment and whether vegetation affects composition of the ant community. Our results show that taxonomic and functional diversity of plant and ant communities are influenced by the environment. While vegetation has no effect on ant communities, we found plant and ant community composition differed across the two ecosites, filtering ant and plant species according to their functional traits, even at a small spatial scale. Our findings imply that small-scale monitoring is needed to effectively conserve priority habitats, especially for those that comprise multiple microhabitats. 


\section{Small-scale drivers on plant and ant diversity in a grassland habitat through a multifaceted approach}

2 Mugnai Michele ${ }^{1 *}$, Frasconi Wendt Clara ${ }^{1}$, Balzani Paride ${ }^{1,2}$, Ferretti Giulio ${ }^{1}$, Dal Cin Matteo ${ }^{1}$, Masoni Alberto ${ }^{1}$,

3 Frizzi Filippo ${ }^{1}$, Santini Giacomo ${ }^{1}$, Viciani Daniele ${ }^{1}$, Foggi Bruno ${ }^{1}$, Lazzaro Lorenzo ${ }^{1}$

$4 \quad{ }^{1}$ Department of Biology, University of Florence, Via G. La Pira 4, 50121 Firenze, Italy

5 '2University of South Bohemia in České Budějovice, Faculty of Fisheries and Protection of Waters, South Bohemian

6 Research Center of Aquaculture and Biodiversity of Hydrocenoses, Zátiší 728/II, 38925 Vodňany, Czech Republic.

7 E-mail:michele.mugnai@unifi.it

8 *corresponding author

9 Abstract

10 Semi-natural grasslands are characterized by high biodiversity and require multifaceted approaches to monitor their 11 biodiversity. Moreover, grasslands comprise a multitude of microhabitats, making the scale of investigation of 12 fundamental importance. Despite their wide distribution, grasslands are highly threatened and are considered of high 13 conservation priority by Directive no. 92/43/EEC. Here, we investigate the effects of small-scale ecological 14 differences between two ecosites present within the EU habitat of Community Interest of semi-natural dry grasslands on calcareous substrates (6210 according to Dir. 92/43/EEC) occurring on a Mediterranean mountain. We measured taxonomic and functional diversity of plant and ant communities, evaluating the differences among the two ecosites, how these differences are influenced by the environment and whether vegetation affects composition of the ant community. Our results show that taxonomic and functional diversity of plant and ant communities are influenced by the environment. While vegetation has no effect on ant communities, we found plant and ant community composition differed across the two ecosites, filtering ant and plant species according to their functional traits, even at a small spatial scale. Our findings imply that small-scale monitoring is needed to effectively conserve priority habitats, especially for those that comprise multiple microhabitats.

23 Keywords: Biodiversity, Community, Functional traits, Mediterranean, Multi-taxa, Priority habitat, Taxonomic diversity 
26

27

28

29

30

31

32

33

34

35

36

37

38

39

40

41

42

43

44

45

46

47

48

49

50

51

52

53

54

55

56

57

58

59

60

61

62

63

64

65

66

67

68

69

70

71

72

73

74

\section{Introduction}

Semi-natural grasslands are habitats with very high species richness, representing biodiversity hotspots in temperate Europe (Wilson et al. 2012). The multitude of microhabitats sustaining a high biodiversity (Habel et al. 2013) justify the high conservation value of these habitats (Dengler et al. 2014). Alongside the richness of plant species, grassland environments are also important reservoirs of animal biodiversity (Zulka et al. 2014; Ambarlı et al. 2016), in particular of invertebrate groups (Van Swaay, 2002; Weiss et al. 2013; Lacasella et al., 2015).

Despite their ecological importance, these habitats are undergoing a rapid decline due to abandonment, land use intensification and afforestation (Burrascano et al. 2013; Habel et al. 2013), which may lead to complex patterns of vegetation changes (Diekmann et al. 2019), including in some cases the simplification of their flora and fauna (Hilpold et al., 2018). This is particularly alarming, given that several threatened species belonging to different trophic groups are associated with these ecosystems (Dengler et al., 2014). For example, 59\% of the 152 European bird species encountered in grasslands are threatened (Nagy, 2009). Therefore, grasslands are listed as high conservation priority in the Habitats Directive (Dir. 92/43/EEC).

Spatial scale has a critical role in structuring biodiversity (Irmler and Hoernes 2003; Keil et al., 2011 ; Carey et al. 2017; Jarzyna and Jetz, 2018; Kral et al. 2018): changes at the small scale may not reflect changes in biodiversity at a larger scale (Crawley and Harral, 2001; Hooper et al., 2005; Chase and Knight, 2013), and different abiotic and biotic filters, acting at different spatial scales, may have a determinant role structuring community composition (Menegotto et al., 2019). For example, in grassland habitats and at large spatial scale, factors such as management types and intensity determine differences in vegetation structure (Auestad et al. 2008). On the other hand, at a small scale, plant species composition resulted to be more affected by edaphic factors, e.g. soil moisture, depth and nutrients content (Auestad et al. 2008; Turtureanu et al. 2014). Furthermore, biodiversity metrics may respond differently to the spatial scale of analysis. For example, while species richness is generally considered one of the main measures of biodiversity, this metric is scale dependent (Belmaker and Jatz, 2010) and may not always depict changes in biodiversity at different spatial scales (Hewitt et al., 2009; Chase et al., 2019). Thus, rather than species richness alone, trait-based metrics may be used in a complementary way, as they may better inform on biodiversity changes across different spatial scales (e.g. Wong et al., 2019).

Traits have a universal approach, as they do not rely on species taxonomic identity, they inform on ecosystem multifunctionality and services and they more easily and rapidly respond to environmental changes (Violle et al., 2014; Gagic et al., 2015). Moreover, grassland communities' functional composition has been shown to respond also to spatial scale of investigation. For example, Bello et al. (2013) found that from the finest (within $50 \mathrm{x} 50 \mathrm{~cm}$ plots) to the broadest scale (area of $22 \mathrm{~km}^{2}$ ), plant species traits ranged respectively from different values (divergence), to similar values (convergence), and finally to no significant differences. Additionally, plant traits are related to different environmental factors, which may influence plant community composition. For example plant height $(\mathrm{H})$ is related to competition for light (Díaz et al. 2016), seed mass (SM) to competition among seedlings and chances of establishment (Westoby 1998; Díaz et al. 2016), specific leaf area (SLA) to resource exploitation (Wright et al. 2004), leaf drymatter content (LDMC) to environmental productivity and disturbance (Hodgson et al. 2011; Pérez-Harguindeguy et al. 2013) and leaf area (LA) hints around the implications on the regulation of leaf temperature and water use efficiency during photosynthesis (Díaz et al. 2016). Recently, Pierce et al. (2017) showed that the measurement of only three leaf traits (LA, SLA and LDMC) can effectively represent interspecific variation in plant size and conservative vs. acquisitive resource economics and that these can be used to reasonably deduce the position of individuals in the CSR framework according to Grime's Competitive Stress-tolerant Ruderal (CSR) theory (Grime 1977; Grime and Pierce 2012).

To assess the ecological role of animal community within grassland habitats, many different groups of invertebrates have been proposed and used (e.g. De Deyn et al. 2003; Barber et al. 2017; Horváth et al. 2019). Among these, ants are shown to be particularly suitable. Ants are important ecosystem engineers, because they modify their surrounding environment and upper and lower trophic levels (Wills and Landis, 2018; De Almeida et al., 2020) and they are used as ecological indicators, because they "respond (or anticipate) to environmental change and represent other taxa" (Ellison, 2012). Besides competition, climatic and environmental variables influence ant communities and predict changes in ant biodiversity at regional and local scale (Sanders et al., 2007; Dunn et al., 2009; Dröse et al., 2019;

PeerJ reviewing PDF | (2021:07:63673:1:0:NEW 11 Oct 2021) 
75 Frasconi Wendt et al., 2020). Accordingly, ant functional traits provide important ecological information, for example:

76 Weber's length (WL) is indicative of ant body size and is related to ant metabolism and thermal tolerance (Peters,

77 1983; Verble-Pearson et al., 2015); head length (HL) may be indicative for ant diet preferences, with granivorous

78 species being characterized by longer heads (Yates et al., 2014); relative leg length (RLL), which corresponds to the

79 leg length divided by head length, is related to body size, according to the size-grain hypothesis (Kaspari and Weiser,

80 1999), and on the way ants perceive their environment (Gibb and Parr, 2013); diet trait stands for food preferences

81 and is influenced by resource availability (Arnan et al., 2014); trait behaviour refers to the dominant and subordinate

82 behaviour of ants and is related to the thermal tolerance (Cerdá et al., 1998). For this reason, the inclusion of multiple

83 taxonomic groups allows to better disentangle the processes shaping the high biodiversity of grassland habitats

84 (Turtureanu et al. 2014).

85 Indeed, ants' and plants' diversity indices were shown to be good ecological indicators for the whole grassland 86 community (Peters et al., 2016). These two communities are strictly connected and as habitat heterogeneity increases,

87 so does resource availability, nesting possibilities and microclimatic conditions that may in turn support a higher 88 species richness and functional diversity (e.g. Nooten et al. 2019). Furthermore, recently Caddy-Retalic et al. (2018) 89 reported a decoupled response of plant and ant community composition under climate change, thus special attention 90 should be given to these two taxa.

91 To assess how small-scale differences drive changes in communities' structure, both in terms of species and functional 92 traits, we investigated a species-rich semi-natural grassland (Habitat 6210 Semi-natural dry grasslands and scrubland 93 facies on calcareous substrates (Festuco-Brometalia); Habitats Directive). In particular, we aimed to verify:

1) whether small-scale ecological differences within the same habitat affect plants and ants. Particularly we expected that small-scale differentiation in two different ecosites comprised in Habitat 6210 individuates two ecological contexts, which may affect plant and ant species and trait composition;

2) the relative relationship among these key groups and the environment, following the framework developed by Frenette-Dussault et al. (2013). In particular, we expected that the different environments affect plant community composition and functions, and that the environment influences indirectly ant communities through changes in plant assemblage. This included assessing which ant traits are influenced by the environment too.

\section{Materials and Methods}

\section{Study site}

104 The study was conducted in the protected area of "Monti della Calvana" (43.915659N, 11.165627E), a Special Area

105 of Conservation (SAC) under Habitat Directive (Natura 2000 code: IT5150001). The study area is a calcareous 106 mountain range located at around $40 \mathrm{~km}$ from Florence (Italy) with a maximum elevation of $916 \mathrm{~m}$ a.s.l. Annual mean temperature is $6.2{ }^{\circ} \mathrm{C}$ and annual precipitation $1023 \mathrm{~mm}$ (Karger et al. 2017). The sampling was conducted in the summital area of the landform, within grasslands classified as Habitat 6210 according to the HaSCITu (Habitat in the Sites of Conservation Interest in Tuscany) program (http://www.regione.toscana.it/-/la-carta-degli-habitat-nei-sitinatura-2000-toscani) and affected by low grazing intensity. A grassland patch of about $1.5 \mathrm{~km}^{2}$ was outlined within the habitat and, through satellite photo interpretation, it has been divided into two (of $0.75 \mathrm{~km}^{2}$ area each) contiguous but definable ecosites, characterized by different substrates (Fig. 1). One ecosite was characterized by inclination $>$ $15^{\circ}$ and shallow soils with outcropping rocks (Rocky hereafter) while the other one for inclination $<15^{\circ}$ and deep

114 soils (Deep hereafter). Despite the whole area was covered by the same grassland habitat, it resulted as easily divisible through photo interpretation into the two ecosites thanks to their topographical distinction (i.e. Deep consisted in the summital part of area while Rocky consisted in the south facing slope of the landform). The distinction into two ecosites was considered as a differentiation at a small scale of the grassland habitat present in the area.

\section{Sampling}

119 Vegetation survey and sampling for plant traits were carried out in May-July 2019. For each ecosite we randomly 120 placed 10 (20 in total) $1 \times 1 \mathrm{~m}^{2}$ quadrat plots in which we surveyed plants and measured environmental variables. 
121

122

123

124

125

126

127

128

129

130

131

132

133

134

135

136

137

138

139

140

141

142

143

144

145

146

147

148

149

150

151

152

153

154

155

156

157

158

159

160

161

162

163

164

165

166

167

168

Following EDGG protocol (European Dry Grassland Group, see Dengler et al. 2016), plant species cover was visually estimated with a precision of $0.1 \%$. As environmental variables, we measured microrelief (perpendicular distance in $\mathrm{cm}$ between lowest and highest ground points), vegetation cover (\%), litter cover (\%), soil depth (average from 5 replicates in $\mathrm{cm}$ ) and vegetation height (average from 5 replicates in $\mathrm{cm}$ ). We selected a set of leaf traits (LA, SLA and LDMC) together with plant height $(\mathrm{H})$, given their responses to environmental factors at a small spatial scale. In addition, we included seed mass (SM) for its ecological relevance and for its link with myrmecochory and predation by ants (Boulay et al. 2007; Thomson et al. 2010; Pearson et al. 2014). For each plot we measured functional traits of plant species whose coverage summed up to the $80 \%$ of the total vegetation coverage (50 plant species in total), considering that they functionally represent the whole flora occurring in the plot (see Pérez-Harguindeguy et al. 2013). For each of these plant species, we measured in the field the height $\mathrm{H}$ of five individuals that were also collected; leaves were immediately immersed in cool deionized water and processed for measurement within 24 hours after collection. We subsequently measured the following traits: (a) Leaf Fresh Weight (LFW); (b) LA, measured after digitizing the leaf outline (1200 dpi) using ImageJ v. 1.51 software (Schneider et al. 2012); and (c) Leaf Dry Weight (LDW), after $72 \mathrm{~h}$ at $70{ }^{\circ} \mathrm{C}$ in an oven. Leaves' weight was measured with an analytical balance, accurate to $0.01 \mathrm{mg}$. For each leaf, we calculated the SLA according to the formula SLA $=$ LA/LDW and the LDMC according to the formula LDMC $=\mathrm{LDW} / \mathrm{LFW}$. LA, SLA and LDMC were measured for 5 individuals of each species and 3-5 leaves for each individual. Values of SM were retrieved from LEDA (Kleyer et al. 2008) and BROT (Tavşanoğlu and Pausas 2018) databases. Leaf functional trait values of two species (Erodium cicutarium and Carduus nutans) were not obtained from field sampling, therefore they were retrieved from TRY (Kattge et al. 2020) and BROT (Tavşanoğlu and Pausas 2018) databases.

Ant sampling was carried out in July 2019. We placed one pitfall trap at the corner of the same quadrat plots used for vegetation surveys, for a total of 40 pitfall traps per ecosite. Pitfall traps consisted of $50 \mathrm{ml}$ Falcon ${ }^{\circledR}$ tube, with a diameter of $30 \mathrm{~mm}$, filled with an $80 \%$ diluted ethanol and $2 \%$ glycerol solution and buried in the ground so that the rim of the trap was at the same level as the soil surface. The traps were re-collected after seven days and brought to the laboratory, where we identified ants to the species level (Czechowski et al., 2012; Lebas et al., 2016).

To assess the functional composition of ant communities, we used the following functional traits: Weber's length (WL), head length (HL), relative leg length (RLL), diet (generalist, seed or sugar based) and behaviour (dominant or subordinate). For the continuous traits (WL, HL and RLL) we measured and averaged them on 15 individuals per species. When species accounted for less than 15 individuals, we measured all available specimens. As for polymorphic species, such as Messor capitatus, M. ibericus and Pheidole pallidula, we measured 10 individuals per caste and then the values were averaged per species. We retrieved the categorical (diet) and binary (behaviour) traits from the available literature (Arnan et al. 2014; Parr et al., 2017; Frasconi Wendt et al., 2020).

\section{Data analysis}

To assess whether the two different ecosites individuated through photointerpretation actually reflect different ecological conditions, we used two types of analyses. First, we performed an analysis of variance (ANOVA) after checking the assumptions (using Shapiro-Wilk normality test, Bartlett test for of homogeneity of variances and Durbin-Watson test for autocorrelated errors) for each environmental variable to check for differences between ecosites. Litter cover has been log-transformed before analyses. The only variable that did not fulfill all the assumptions was vegetation cover, for which we used the Welch One-way ANOVA (not assuming equal variances). Second, we calculated Grime's CSR ecological strategies for each plot based on plant leaf traits. We used the StrateFy tool (Pierce et al. 2017) to obtain CSR values for each plant species and subsequently we calculated the CommunityWeighted Mean (CWM, see below) of such values for each plot. Using CSR values as coordinates, plots were displayed in a ternary diagram (Pierce et al. 2017). In order to test whether the two contexts differ in terms of ecological strategies, each of the three CSR values were tested using ANOVA, after assessing the assumption of ANOVA. Only $\mathrm{R}$ coordinates did not fulfill all the assumptions, hence the Welch One-way ANOVA (not assuming equal variances) were performed. Moreover, R coordinates were log-transformed before analyses.

We used ant incidence data, corresponding to the number of pitfall traps in each quadrat that contained a given species, as ant abundance data may be biased by the proximity of the pitfall traps to an ant nest (Gotelli et al., 2011).

PeerJ reviewing PDF | (2021:07:63673:1:0:NEW 11 Oct 2021) 
169

170

171

172

173

174

175

176

177

178

179

180

181

182

183

184

185

186

187

188

189

190

191

192

193

194

195

196

197

198

199

200

201

202

203

204

205

206

207

208

209

210

211

212

213
Plant and ant functional structure were assessed using the CWM, which measures the mean trait value for the whole community weighted by the abundance of the species carrying the trait (Garnier et al., 2007).

Differences in plant and ant community compositions between the two habitat ecosites were evaluated using nonmetric multidimensional scaling (nMDS) based on the Bray-Curtis dissimilarity index (McCune et al., 2002) and their significance was assessed throughout a permutational multivariate analysis of variance (PERMANOVA) with 9999 permutations. Subsequently, CWMs of plant and ant traits were fitted onto species ordinations using function envfit (Oksanen et al. 2020) to evaluate the direction and magnitude of traits variation within the two communities.

To measure the relationship between environmental variables, plant, and ant communities, we performed simple and partial Mantel's tests, as proposed by Frenette-Dussault et al. (2013). In simple Mantel tests, correlations are performed between two distance matrices, whereas the partial Mantel test assesses the relationships between two distance matrices, while controlling for a third matrix. We used Bray-Curtis dissimilarity for the plant and ant species distance matrices, and Euclidean distance for environmental (Rocky and Deep ecosites) and traits (CWMs) distance matrices. Environmental matrix was built using distances between ecosites, while for the trait matrix we used CWMs of plant and ant traits.

Finally, to evaluate the relationship between environmental variables, ant species and ant functional traits, we performed a fourth-corner analysis (Brown et al., 2012) followed by the least absolute shrinkage and selection operator (LASSO) to obtain the most parsimonious model (Wang et al., 2017). This analysis, which provides a model for species abundance (in our case species incidence) as a function of environmental factors, functional traits and their interaction, quantifies the strength and the significance of the environment-trait interactions and identifies which interactions drive species abundances. The resulting matrix (fourth-corner) shows the interaction coefficients between the environmental variables and the functional traits (Brown et al., 2014).

nMDS and Mantel tests were conducted within the R package vegan (Oksanen et al. 2020) and the fourth-corner analysis within package mvabund (Wang et al. 2020). All analyses were performed using R 3.5.2 (R Core Team 2017).

\section{Results}

The two ecosites resulted as characterized by similar species richness, for both plant and ant communities, with a slightly higher number of species in Rocky ecosite: 94 plant and 16 ant species in Deep ecosite, and 98 plant and 19 ant species in Rocky ecosite. In supplementary information (S1) are provided the sample-size-based rarefaction curves for both ecosites and plant and ant communities.

The environmental variables used to describe the two ecosites showed a significant difference between Rocky and Deep ecosites. In particular, herb coverage and soil depth were higher in Deep ecosite, while microrelief was higher in Rocky ecosite (Fig. 2 and Tab. 1). Moreover, CSR values between ecosites were statistically different (Tab. 1), with plots from Deep ecosite more characterized by R strategy and Rocky plots by C and S strategies (Figs. 2 and 3).

Both plant and ant communities showed significant differentiation in species composition between Rocky and Deep ecosites, as the points representing them were mapped at the opposite extremes of the ordination space (Fig. 4, Tab. 2). The nMDSs showed a high goodness of fit already with two dimensions both for plant (stress 0.15 , non-metric R2 $=0.976$ ) and ant communities (stress 0.12 , non-metric $\mathrm{R} 2=0.987$ ). Moreover, traits fitted onto ordinations showed some patterns in relation to the two ecosites, and most of them were statistically significant (Tab. 3). In particular, regarding plant traits, Rocky ecosite results characterized by higher LA and $\mathrm{H}$, while for ant traits we found higher values of WL, HL, RLL, subordinate behaviour and generalist diet in Deep ecosite.

Simple and partial Mantel tests indicated two similar scenarios for taxonomic and functional community composition of both groups (Tab. 4). Correlations indicated that the environment (ecosites Rocky and Deep) but not vegetation composition had a direct effect on ant taxonomic and functional communities. Despite the taxonomic and functional approaches having similar outcomes, the first one shows a stronger correlation for environment-vegetation than for environment-ant, while the latter one reveals a stronger association for environment-ant rather than for environmentvegetation.

PeerJ reviewing PDF | (2021:07:63673:1:0:NEW 11 Oct 2021) 
214 The fourth-corner analysis results showed some significant relationships between ant functional traits and environment

215 variables (Fig. 5). For example, body size traits were correlated with variables that describe environmental

216 heterogeneity, with WL positively correlating with herb coverage. We also found a strong negative correlation

217 between granivorous diets and soil depth.

\section{Discussion}

219 According to our results, within the same grassland habitat and at a small-scale, we could identify two ecosites in 220 which ecological differences led to different plant and ant communities. The discrimination of the two ecosites, which 221 was initially based on photointerpretation, geomorphology (i.e. slope) and on a physionomical basis (i.e. vegetation coverage), was confirmed by ecologically different and relevant variables and by different CSR profiles at a smallscale. Indeed, CSR strategies are known to respond to ecological constraints at various spatial resolutions, at global (Pierce et al. 2017), medium (Rosenfield et al. 2019) and local scale (Negreiros et al. 2014; but see Rosado and de Mattos 2017). The absence of other ecological factors, e.g. soil $\mathrm{pH}$, soil moisture and thermal conditions, may represent a limitation to our study. Such ecological factors are known to shape plant and ant communities, as they directly influence nutrient and water availability, movement and ability to find food resources (e.g Wiescher et al. 2012; Dengler et al. 2014; Arnan et al., 2015a). However, the environmental variables used in this study are of primary importance in driving structure of grassland communities and widely used in similar research (e.g. Bernard-Verdier et al. 2012; Turtureanu et al. 2014).

The two ecosites were characterized by distinct plant and ant communities. Plant species composition is well known to respond to ecological differences at different scales (Auestad et al. 2008; Bello et al. 2013; Turtureanu et al. 2014). In our case, Deep ecosite is characterized by nearly exclusive species (Lolium perenne, Cerastium glomeratum, Salvia pratensis, Phleum pratense, Centaurea solstitialis) with high ruderality (Pignatti et al. 2017). Plant species composition at Rocky ecosite is more variable and with a few species typical of unproductive rocky grasslands (e.g Trifolium stellatum and Crepis neglecta). These results are consistent with the ecological characterization accomplished through CSR strategies. With regards to ants, we found two different ant communities in the two ecosites, suggesting that ant assemblage reflects different habitats and conditions even at small-scale, as found by other studies (Frasconi Wendt et al. 2021a; Frizzi et al. 2021). We sampled mainly generalist species (e.g. Formica cunicularia and Myrmica spp.) in the Deep ecosite, whereas the Rocky ecosite was characterized by dominant species (such as Tapinoma erraticum and T. madeirense). These results support some recent studies from karstic environments in Hungary showing that both ant and plant species and functional composition (in terms of environmental requirements) respond to fine-scale microhabitat differences, namely between the inner parts of natural depressions (dolines) and the surrounding plateau areas, providing different microclimatic conditions and a high environmental heterogeneity (Bátori et al., 2019, 2020).

The environmental differentiation between the two ecosites was related to both plant and ant taxonomic and functional composition. The influence of the environment on plant composition can be explained by the ecological differences between the two ecosites. Soil depth and microrelief are two important drivers of plant community assembly both taxonomically and functionally (Bernard-Verdier et al. 2012; Turtureanu et al. 2014). Moreover, the environmental differences between the two ecosites may allow to infer on the distinct ecological responses by the plant communities. Shallower soils with a prevalence of abiotic fraction (i.e. outcropping rocks, stones and gravel; namely Rocky ecosite), selected for more stress-tolerant plant communities, whose species deal with less resources availability (mainly water) and for this reason result in higher LDMC values. Similarly, steeper slopes are characterized by lower water availability and host communities in which environmental filtering is selecting more stress-tolerant sets of traits, such as higher LDMC (Bricca et al., 2021). This effect could be increased also by the south-facing aspect of Rocky ecosite, according to the relationship between topographic exposure and vegetation extensively reported in literature (e.g. Li et al., 2011; Valencia et al., 2015). On the contrary, the Deep ecosite is characterized by flatter and deeper soils, where soil resources are more abundant, and vegetation thrives and forms dense cover. Here, plant species showed higher SLA and communities were characterized by a higher ruderality, probably linked to higher levels of disturbance. Indeed, despite both ecosites are subjected to a low intensity of grazing, Deep ecosite could be more affected by 
261

262

263

264

265

266

267

268

269

270

271

272

273

274

275

276

277

278

279

280

281

282

283

284

285

286

287

288

289

290

291

292

293

294

295

296

297

298

299

300

301

302

303

304

305

306

307

308 disturbance as a result of the low inclination of slope, which not only mitigates the north-facing aspect but also offer more viable paths for hikers and livestock.

While the direct effect of the environment on vegetation was expected and extensively demonstrated, the direct effect of the environment on ant community composition is debated. For example, Frenette-Dussault et al. (2013) findings highlight the presence of a direct effect of vegetation and only an indirect effect (through vegetation structure) of the environment on ant species and trait composition (Frenette-Dussault et al. 2013). On the contrary, other studies support the trait-environment constraints and the role of the environment acting as the primary filter on ant composition (Wiescher et al., 2012; Boet et al., 2020). Indeed, the strong environment-ant association and the role of environmental variables influencing ant taxonomic and functional diversity at different scales has been acknowledged in past studies and in different ecosystems too (Wiescher et al., 2012; Frenette-Dussault et al., 2013; Arnan et al., 2014, 2015b; Nooten et al., 2019). Microrelief, slope inclination, vegetation height and cover, and soil composition are important variables describing the ecological conditions occurring in grassland habitats where sampled ants live and forage, and they are good predictors of ant community composition and diversity along environmental gradients in different ecosystems (Debuse et al., 2007; Pacheco and Vasconcelos, 2012; Arnan et al., 2014; Mauda et al., 2018). For example, Deák et al. (2020) found that grassland habitats characterized by steeper slopes and more topographically heterogeneous host more diverse arthropod communities, with ant being one of the main groups. Therefore, the distinct ant communities may be explained by the different environmental compositions of the two ecosites (Bátori et al., 2020), meaning that at small-spatial scale, environmental parameters, which may describe the microhabitat and microclimatic conditions, are stronger than vegetation at driving ant community composition. Nevertheless, it must be considered that the evaluation of other vegetation features may better explain the actual variation of ant communities.

The fourth-corner analysis revealed that ant body size was not related to the microrelief and instead increased with herb cover, contradicting past studies (Nooten et al., 2019) and the size-grain hypothesis (Kaspari and Weiser, 1999): having large body size may represent an impediment for the movements and foraging of ants in a denser environment, such as the one characterized by a higher herb cover, whereas in a more open and planar environment, body size increases (Gibb and Parr, 2010, 2013). Two possible explanations may be given for these contrasting results. First, our spatial scale of analysis, although at a small-scale, may not fully reveal the habitat heterogeneity and soil rugosity as perceived by ants. Nooten et al. (2019) suggested that contrasting outcomes of the environment-ant relationship may arise because of the different ways habitat complexity is measured in distinct studies. Second, other unmeasured variables, such as climatic factors, rather than herb cover per se may explain changes in ant body size (Wiescher et al., 2012; Arnan et al., 2014). The other strong relationship found in the fourth-corner analysis, concerned the negative association between seed-based diet and soil depth. The dominance of the seed-based diet in Rocky ecosite, which is characterized by shallow soils, may be driven by the higher occurrence of harvester ant species belonging to the genus Messor compared to Deep ecosite. In fact, species of the Messor genus were collected exclusively in a few sampling points in the Deep ecosite. Other soil characteristics, such as texture, clay content and chemistry may be better related to ant diversity (Bestelmeyer and Wiens, 2001; Debuse et al., 2007). From a conservation perspective, our results value the importance of protecting the local rich-plant and -ant communities within each ecosite of this semi-natural grassland. This may be achieved through the maintenance of habitat heterogeneity, namely different microclimatic and microhabitat conditions, which seem to play an essential role in the conservation of plants and ants in similar grassland ecosystems too (Bátori et al., 2019). However, these fine-scale microhabitat differences and the biodiversity associated with this SAC site may be threatened because of the loss or intensification of low-intensity anthropogenic practices. This is particularly alarming, given that the site is under the Habitat Directive (Natura 2000 code: IT5150001) and a SAC, thus, efforts should be deployed to protect this grassland ecosystem even at a small-spatial scale.

\section{Conclusions}

We demonstrated that small-scale ecological differentiation into ecosites of a grassland habitat affects key groups, i.e. plants and ants, in terms of species composition and functional traits. Furthermore, we found that the environment directly influenced taxonomic and functional composition of both groups, while vegetation seemed to play a minor

PeerJ reviewing PDF | (2021:07:63673:1:0:NEW 11 Oct 2021) 
309

310

311

312

313

314

315

316

317

318

319

320

321

322

323

324

325

326

327

328

329

330

331

332

333

334

335

336

337

338

339

340

341

342

343

344

345

346

347

role in shaping the assembly of ant communities, at least at a small-scale. These results highlighted the importance of using complementary biodiversity approaches (i.e. taxonomic and functional). Moreover, plant and ant taxa revealed to be suitable key groups for multi taxa studies. Lastly, our results showed that considering only the habitat type in biodiversity studies can lead to coarse approximations, thus emphasizing the importance of small-scale monitoring of key biodiversity groups for the effective assessment of environmental changes on biodiversity.

\section{Acknowledgements}

The authors want to thank Fabrizio Rigato for ant species confirmation.

\section{References}

Ambarlı D, Zeydanlı U, Balkız Ö, et al (2016) An overview of biodiversity and conservation status of steppes of the Anatolian Biogeographical Region. Biodivers Conserv 25:2491-2519. https://doi.org/10.1007/s10531-016$1172-0$

Arnan X, Cerdá X, Retana J (2014) Ant functional responses along environmental gradients. J Anim Ecol 83:13981408. https://doi.org/10.1111/1365-2656.12227

Arnan X, Blüthgen N, Molowny-Horas R, Retana J (2015a) Thermal characterization of European ant communities along thermal gradients and its implications for community resilience to temperature variability. Frontiers in ecology and evolution 3:138.

Arnan X, Cerdá X, Retana J (2015b) Partitioning the impact of environment and spatial structure on alpha and beta components of taxonomic, functional, and phylogenetic diversity in European ants. PeerJ 3:e1241. https://doi.org/10.7717/peerj.1241

Auestad I, Rydgren K, Økland RH (2008) Scale-dependence of vegetation-environment relationships in semi-natural grasslands. J Veg Sci 19:139-148. https://doi.org/10.3170/2007-8-18344

Barber NA, Lamagdeleine-Dent KA, Willand JE, Jones HP, McCravy KW (2017) Species and functional trait reassembly of ground beetle communities in restored grasslands. Biodivers Conserv 26(14):3481-3498.

Bátori Z, Vojtkó A, Maák IE, Lörinczi G, Farkas T, Kántor N, Tanács E, Kiss PJ, Juhász O, Módra G, Tölgyesi C, Erdős L, Aguilon DJ, Keppel G (2019). Karst dolines provide diverse microhabitats for different functional groups in multiple phyla. Sci Rep 9:1-13.

Bátori Z, Lőrinczi G, Tölgyesi C, Módra G, Juhász O, Aguilon DJ, Vojtkó A, Valkó O, Deák B, Erdős L, Maák IE (2020). Karstic Microrefugia Host Functionally Specific Ant Assemblages. Front Ecol Evol 8:482.

Bello F de, Vandewalle M, Reitalu T, et al (2013) Evidence for scale- and disturbance-dependent trait assembly patterns in dry semi-natural grasslands. J Ecol 101:1237-1244. https://doi.org/10.1111/1365-2745.12139

Belmaker J, Jetz W (2010.) Cross-scale variation in species richness-environment associations. Global Ecol Biogeogr 20(3):464-474. https://doi.org/10.1111/j.1466-8238.2010.00615.x

Bernard-Verdier M, Navas ML, Vellend M, Violle C, Fayolle A, Garnier E (2012) Community assembly along a soil depth gradient: contrasting patterns of plant trait convergence and divergence in a Mediterranean rangeland. Journal of Ecology 100(6):1422-1433.

Bestelmeyer BT, Wiens JA (2001) Ant biodiversity in semiarid landscape mosaics: The consequences of grazing vs. natural heterogeneity. Ecol Appl 11:1123-1140.

Bishop TR, Robertson MP, van Rensburg BJ van, Parr CL (2014) Elevation-diversity patterns through space and time: ant communities of the Maloti-Drakensberg Mountains of southern Africa. J Biogeogr 41:2256-2268. 
348

349

350

351

352

353

354

355

356

357

358

359

360

361

362

363

364

365

366

367

368

369

370

371

372

373

374

375

376

377

378

379

380

381

382

383

384

385

Bricca A, Carranza ML, Varricchione M, Cutini M, Stanisci A (2021) Exploring Plant Functional Diversity and Redundancy of Mediterranean High-Mountain Habitats in the Apennines. Diversity 13(10):466.

Brown AM, Warton DI, Andrew NR, Binns M, Cassis G, Gibb H (2014) The fourth-corner solution-using predictive models to understand how species traits interact with the environment. Methods in Ecology and Evolution 5(4):344-352.

Boet O, Arnan X, Retana J (2020) The role of environmental vs. biotic filtering in the structure of European ant communities: A matter of trait type and spatial scale. PloS one 15(2):e0228625. https://doi.org/10.1371/journal.pone.0228625

Boulay R, Coll-Toledano J, Manzaneda AJ, Cerdá X (2007) Geographic variations in seed dispersal by ants: are plant and seed traits decisive? Naturwissenschaften 94:242-246. https://doi.org/10.1007/s00114-006-0185$\mathrm{Z}$

Branquinho C, Serrano HC, Nunes A, Pinho P, Matos P (2019) Essential biodiversity change indicators for evaluating the effects of Anthropocene in ecosystems at a global scale. In: Casetta E, Marques da Silva J, Vecchi D (eds) From Assessing to Conserving Biodiversity. History, Philosophy and Theory of the Life Sciences, vol 24. Springer, Cham.

Burrascano S, Anzellotti I, Carli E, Del Vico E, Facioni L, Pretto F, Sabatini FM, Tilia A, Blasi C (2013) Drivers of beta-diversity variation in Bromus erectus semi-natural dry grasslands. Applied Vegetation Science 16(3):404-416.

Caddy-Retalic S, Hoffmann BD, Guerin GR, Andersen AN, Wardle GM, McInerney FA, Lowe AJ (2019) Plant and ant assemblages predicted to decouple under climate change. Diversity and Distributions 25(4):551-567.

Carey JG, Brien S, Williams CD, Gormally MJ (2017) Indicators of Diptera diversity in wet grassland habitats are influenced by environmental variability, scale of observation, and habitat type. Ecol Indic 82:495-504.

Cerdá X, Retana J, Cros S (1998) Critical thermal limits in Mediterranean ant species: trade-off between mortality risk and foraging performance. Functional Ecology 12(1):45-55.

Chase JM, McGill BJ, Thompson PL, Antão LH, Bates AE, Blowes SA, Dornelas M, Gonzalez A, Magurran AE, Supp SR, Winter M, Bjorkman AD, Bruelheide H, Byrnes JEK, Cabral JS, Elahi R, Gomez C, Guzman HM, Isbell F, Myers-Smith IH, Jones HP, Hines J, Vellend M, Waldock C, O'Connor, M. (2019) Species richness change across spatial scales. Oikos 128(8):1079-1091.

Chase JM, Knight TM (2013) Scale-dependent effect sizes of ecological drivers on biodiversity: why standardised sampling is not enough. Ecol Lett 16:17-26.

Consorti R (2009) I Carabidae dei Monti della Calvana (Toscana). Onychium 7:44-47.

Crawley MJ, Harral JE (2001) Scale dependence in plant biodiversity. Science 291(5505):864-868.

Czechowski W, Radchenko A, Czechowska W Vepsäläinen K (2012) The ants of Poland with reference to the myrmecofauna of Europe. Museum and Institute of Zoology at the Polish Academy of Sciences, pp 496.

De Almeida T, Mesléard F, Santonja M, Gros R, Dutoit T, Blight O (2020) Above-and below-ground effects of an ecosystem engineer ant in Mediterranean dry grasslands. Proc Royal Soc B 287(1935):1840.

De Deyn GB, Raaijmakers CE, Zoomer HR, Berg MP, Ruiter PC de, Verhoef HA et al. (2003) Soil invertebrate fauna enhances grassland succession and diversity. Nature 422(6933):711-713.

PeerJ reviewing PDF | (2021:07:63673:1:0:NEW 11 Oct 2021) 
386

387

388

389

390

391

392

393

394

395

396

397

398

399

400

401

402

403

404

405

406

407

408

409

410

411

412

413

414

415

416

417

418

419

420

421

422

423

424

425

426

Debuse VJ, King J, House AP (2007) Effect of fragmentation, habitat loss and within-patch habitat characteristics on ant assemblages in semi-arid woodlands of eastern Australia. Landscape Ecology 22(5):731-745.

Dengler J, Boch S, Filibeck G, et al (2016) Assessing plant diversity and composition in grass- lands across spatial scales: the standardised EDGG sampling methodology. Bull Eurasian Dry Grassl Group 18

Dengler J, Janišová M, Török P, Wellstein C (2014) Biodiversity of Palaearctic grasslands: a synthesis. Agric Ecosyst Environ 182:1-14. https://doi.org/10.1016/j.agee.2013.12.015

Díaz S, Kattge J, Cornelissen JHC, et al (2016) The global spectrum of plant form and function. Nature 529:167171. https://doi.org/10.1038/nature16489

Diekmann M, Andres C, Becker T, Bennie J, Blüml V, Bullock JM, Culmsee H, Fanigliulo M, Hahn A, Heinken T, Leuschner C, Luka S, Meißner J, Müller J, Newton A, Peppler-Lisbach C, Rosenthal G, van den Berg LJL, Vergeer P, Wesche K (2019) Patterns of long-term vegetation change vary between different types of seminatural grasslands in Western and Central Europe. Journal of Vegetation Science 30(2):187-202.

Dröse W, Podgaiski LR, Dias CF, Mendonca MDS Jr (2019) Local and regional drivers of ant communities in forest-grassland ecotones in South Brazil: A taxonomic and phylogenetic approach. PloS one 14(4):e0215310.

Dunn RR, Agosti D, Andersen AN, Arnan X, Brühl CA, Cerdá X, Ellison AM, Fisher BL, Fitzpatrick MC, Gibb H, Gotelli NJ, Gove AD, Guénard B, Janda M, Kaspari M, Laurent EJ, Lessard J-P, Longino JT, Majer JD, Menke SB, McGlynn TP, Parr CL, Philpott SM, Pfeiffer M, Retana J, Suarez AV, Vasconcelos HL, Weiser MD, Sanders NJ (2009) Climatic drivers of hemispheric asymmetry in global patterns of ant species richness. Ecol Lett 12:324-333.

Ellison AM (2012) Out of Oz: Opportunities and challenges for using ants (Hymenoptera: Formicidae) as biological indicators in north-temperate cold biomes. Myrmecol News 17:105-119.

Frasconi Wendt C, Nunes A, Verble R, Santini G, Boieiro M, Branquinho C (2020) Using a space-for-time approach to select the best biodiversity-based indicators to assess the effects of aridity on Mediterranean drylands. Ecol Indic 113:106250.

Frasconi Wendt C, Frizzi F, Aiello G, Balzani P, Santini G (2021a) Ant species but not trait diversity increases at the edges: insights from a micro-scale gradient in a semi-natural Mediterranean ecosystem. Ecol Ent. https://doi.org/10.1111/een.13020

Frasconi Wendt C, Nunes A, Köbel M, Verble R, Matos P, Boieiro M, Branquinho C (2021b) Ant functional structure and diversity changes along a post-grazing succession in Mediterranean oak woodlands. Agroforestry Systems 1-12.

Frizzi F, Tucci L, Ottonetti L, Masoni A, Santini G (2021) Day-night and inter-habitat variations in ant assemblages in a mosaic agroforestry landscape. Land 10:179. https://doi.org/10.3390/ land10020179

Frenette-Dussault C, Shipley B, Hingrat Y (2013) Linking plant and insect traits to understand multitrophic community structure in arid steppes. Funct Ecol 27:786-792. https://doi.org/10.1111/1365-2435.12075

Gagic V, Bartomeus I, Jonsson T, Taylor A, Winqvist C, Fischer C, Slade EM, Steffan-Dewenter I, Emmerson M, Potts SG, Tscharntke T, Weisser W, Bommarco R (2015) Functional identity and diversity of animals predict ecosystem functioning better than species-based indices. Proc R Soc B 282(1801):20142620.

Garnier E, Lavorel S, Ansquer P, Castro H, Cruz P, Dolezal J, Eriksson O, Fortunel C, Freitas H, Golodets C, Grigulis K, Jouany C, Kazakou E, Kigel J, Kleyer M, Lehsten V, Leps J, Meier T, Pakeman R, Papadimitriou M, Papanastasis VP, Quested H, Quétier F, Robson M, Roumet C, Rusch G, Skarp C,

Peer) reviewing PDF | (2021:07:63673:1:0:NEW 11 Oct 2021) 
427

428

429

430

431

432

433

434

435

436

437

438

439

440

441

442

443

444

445

446

447

448

449

450

451

452

453

454

455

456

457

458

459

460

461

462

463

464

Sternberg M, Theau J-P, Thébault A, Vile D Zarovali MP (2007) Assessing the effects of land-use change on plant traits, communities and ecosystem functioning in grasslands: a standardized methodology and lessons from an application to 11 European sites. Ann Bot 99:957-985.

Gestri G (2009) Flora vascolare dei Monti della Calvana (Prato, Toscana). Inform Bot Ital 41(1):77-123.

Gibb H, Parr CL (2013) Does structural complexity determine the morphology of assemblages? An experimental test on three continents. PLoS One 8(5):e64005.

Gotelli NJ, Ellison AM, Dunn RR, Sanders NJ (2011) Counting ants (Hymenoptera: Formicidae): Biodiversity sampling and statistical analysis for myrmecologists. Myrmecol News 15:13-19.

Grime JP (1977) Evidence for the Existence of Three Primary Strategies in Plants and Its Relevance to Ecological and Evolutionary Theory. Am Nat 111:1169-1194. https://doi.org/10.1086/283244

Grime JP, Pierce S (2012) The Evolutionary Strategies that Shape Ecosystems. John Wiley \& Sons

Habel JC, Dengler J, Janišová M, et al (2013) European grassland ecosystems: threatened hotspots of biodiversity. Biodivers Conserv 22:2131-2138. https://doi.org/10.1007/s10531-013-0537-X

Hewitt J, Thrush S, Lohrer A, Townsend M (2010) A latent threat to biodiversity: consequences of small-scale heterogeneity loss. Biodivers Conserv 19(5):1315-1323.

Hilpold A, Seeber J, Fontana V, Niedrist G, Rief A, Steinwandter M et al. (2018) Decline of rare and specialist species across multiple taxonomic groups after grassland intensification and abandonment. Biodivers Conserv 27(14):3729-3744.

Hodgson JG, Montserrat-Martí G, Charles M et al (2011) Is leaf dry matter content a better predictor of soil fertility than specific leaf area? Ann Bot 108:1337-1345. https://doi.org/10.1093/aob/mcr225

Hooper DU, Chapin Iii FS, Ewel JJ, Hector A, Inchausti P, Lavorel S et al. (2005). Effects of biodiversity on ecosystem functioning: a consensus of current knowledge. Ecol Monogr 75(1):3-35.

Horváth R, Magura T, Tóthmérész B, Eichardt J, Szinetár C (2019) Both local and landscape-level factors are important drivers in shaping ground-dwelling spider assemblages of sandy grasslands. Biodivers Conserv 28(2):297-313.

Irmler U, Hoernes U (2003) Assignment and evaluation of ground beetle (Coleoptera: Carabidae) assemblages to sites on different scales in a grassland landscape. Biodivers Conserv, 12(7):1405-1419.

Jarzyna MA, Jetz W (2018) Taxonomic and functional diversity change is scale dependent. Nature 9:2565.

Kaspari M, Weiser MD (1999) The size-grain hypothesis and interspecific scaling in ants. Functional ecology 13(4):530-538.

Karger DN, Conrad O, Böhner J, Kawohl T, Kreft H, Soria-Auza RW, Zimmermann NE, Linder HP, Kessler M (2017) Data from: Climatologies at high resolution for the earth's land surface areas. Dryad Digital Repository. doi.org/10.5061/dryad.kd1d4

Kattge J, Bönisch G, Díaz S, et al (2020) TRY plant trait database - enhanced coverage and open access. Glob Change Biol 26:119-188. https://doi.org/10.1111/gcb.14904

Keil P, Pereira HM, Cabral JS, Chase JM, May F, Martins IS, Winter M (2017) Spatial scaling of extinction rates: Theory and data reveal nonlinearity and a major upscaling and downscaling challenge. Glob Ecol Biogeogr 27:2-13.

Peer] reviewing PDF | (2021:07:63673:1:0:NEW 11 Oct 2021) 
465

466

467

468

469

470

471

472

473

474

475

476

477

478

479

480

481

482

483

484

485

486

487

488

489

490

491

492

493

494

495

496

497

498

499

500

501

502

503

Kleyer M, Bekker RM, Knevel IC, et al (2008) The LEDA Traitbase: a database of life-history traits of the Northwest European flora. J Ecol 96:1266-1274. https://doi.org/10.1111/j.1365-2745.2008.01430.x

Kral KC, Hovick T, Limb RF, Harmon JP (2018) Multi-scale considerations for grassland butterfly conservation in agroecosystems. Biol Conserv 226:196-204.

Lacasella F, Gratton C, De Felici S, Isaia M, Zapparoli M, Marta S, Sbordoni V (2015) Asymmetrical responses of forest and "beyond edge" arthropod communities across a forest-grassland ecotone. Biodivers Conserv 24(3):447-465.

Lebas C, Galkowski C, Blatrix R, Wegnez P (2016) Fourmis d'Europe occidentale. Guide Delachaux.

Li X, Nie Y, Song X, Zhang R, Wang G (2011) Patterns of species diversity and functional diversity along the south to north-facing slope gradient in a sub-alpine meadow. Community Ecology 12(2):179-187.

Masoni A, Frizzi F, Brühl C, Zocchi N, Palchetti E, Chelazzi G, Santini G (2017) Management matters: A comparison of ant assemblages in organic and conventional vineyards. Agric Ecosyst Environ 246:175183.

Mauda EV, Joseph GS, Seymour CL, Munyai TC, Foord SH (2018) Changes in landuse alter ant diversity, assemblage composition and dominant functional groups in African savannas. Biodivers Conserv 27(4):947-965.

McCune B, Grace JB, Urban DL (2002) Analysis of ecological communities. MjM Software Design. Gleneden Beach OR USA.

Menegotto A, Dambros CS, Netto SA (2019) The scale-dependent effect of environmental filters on species turnover and nestedness in an estuarine benthic community. Ecology 100(7):e02721.

Nagy S (2009) Grasslands as a bird habitat. In: Veen P, Jefferson R., Smidt J de, Straaten J van der (eds) Grasslands in Europe. KNNV Publishing, pp. 35-41.

Negreiros D, Le Stradic S, Fernandes GW, Rennó HC (2014) CSR analysis of plant functional types in highly diverse tropical grasslands of harsh environments. Plant Ecol 215(4):379-388.

Nooten SS, Schultheiss P, Rowe RC, Facey SL, Cook JM (2019) Habitat complexity affects functional traits and diversity of ant assemblages in urban green spaces (Hymenoptera: Formicidae). Myrmecol News 29:67-77.

Oksanen J, Blanchet FG, Friendly M, et al (2020) vegan: Community Ecology Package. Version 2.5-7URL https://CRAN.R-project.org/package=vegan

Pacheco R, Vasconcelos HL (2012) Habitat diversity enhances ant diversity in a naturally heterogeneous Brazilian landscape. Biodivers Conserv 21(3):797-809.

Parr CL, Dunn RR, Sanders NJ, Weiser MD, Photakis M, Bishop T, Fitzpatrick MC, Arnan X, Baccaro F, Brandão CRF, Chick L, Donoso DA, Fayle TM, Gómez C, Grossman B, Munyai TC, Pacheco R, Retana J, Robinson A, Sagata K, Silva RR, Tista M, Vasconcelos H, Yates M, Gibb H (2017) GlobalAnts: a new database on the geography of ant traits (Hymenoptera: Formicidae). Insect Conserv Diver 10:5-20.

Pearson DE, Icasatti NS, Hierro JL, Bird BJ (2014) Are Local Filters Blind to Provenance? Ant Seed Predation Suppresses Exotic Plants More than Natives. PLOS ONE 9:e103824. https://doi.org/10.1371/journal.pone.0103824

Pérez-Harguindeguy N, Díaz S, Garnier E, et al (2013) New handbook for standardised measurement of plant functional traits worldwide. Aust J Bot 61:167. https://doi.org/10.1071/BT12225

PeerJ reviewing PDF | (2021:07:63673:1:0:NEW 11 Oct 2021) 
504

505

506

507

508

509

510

511

512

513

514

515

516

517

518

519

520

521

522

523

524

525

526

527

528

529

530

531

532

533

534

535

536

537

538

539

540

541

Peters VE, Campbell KU, Dienno G, García M, Leak E, Loyke C, et al. (2016) Ants and plants as indicators of biodiversity, ecosystem services, and conservation value in constructed grasslands. Biodivers Conserv 25(8):1481-1501.

Pierce S, Negreiros D, Cerabolini BEL, et al (2017) A global method for calculating plant CSR ecological strategies applied across biomes world-wide. Funct Ecol 31:444-457. https://doi.org/10.1111/1365-2435.12722

Pignatti S, Guarino R, La Rosa M (2017) Flora d'Italia, Ed. 2, Vol. 1-3. Edagricole, Bologna.

R Core Team (2017) R: A language and environment for statistical computing. R Found. Stat Comput Vienna, Austria.

Rosado BH, Mattos EA de (2017) On the relative importance of CSR ecological strategies and integrative traits to explain species dominance at local scales. Funct Ecol 31(10):1969-1974.

Rosenfield MF, Müller SC, Overbeck GE (2019) Short gradient, but distinct plant strategies: The CSR scheme applied to subtropical forests. J Veg Sci 30(5):984-993.

Sanders NJ, Lessard J-P, Fitzpatrick MC, Dunn RR (2007) Temperature, but not productivity or geometry, predicts elevational diversity gradients in ants across spatial grains. Glob Ecol Biogeogr 16:640-649.

Schneider CA, Rasband WS, Eliceiri KW (2012) NIH Image to ImageJ: 25 years of image analysis. Nat Methods 9:671-675. https://doi.org/10.1038/nmeth.2089

Tavşanoğlu Ç, Pausas JG (2018) A functional trait database for Mediterranean Basin plants. Sci Data 5:180135. https://doi.org/10.1038/sdata.2018.135

Thomson FJ, Moles AT, Auld TD, et al (2010) Chasing the unknown: predicting seed dispersal mechanisms from plant traits. J Ecol 98:1310-1318. https://doi.org/10.1111/j.1365-2745.2010.01724.x

Turtureanu PD, Palpurina S, Becker T, et al (2014) Scale- and taxon-dependent biodiversity patterns of dry grassland vegetation in Transylvania. Agric Ecosyst Environ 182:15-24. https://doi.org/10.1016/j.agee.2013.10.028

Underwood EC, Fisher BL (2006) The role of ants in conservation monitoring: if, when, and how. Biol Conserv 132(2):166-182.

Valencia E, Maestre FT, Le Bagousse-Pinguet Y, Quero JL, Tamme R, Börger L, García-Gómez M, Gross N (2015) Functional diversity enhances the resistance of ecosystem multifunctionality to aridity in Mediterranean drylands. New Phytologist 206(2):660-671.

Van Swaay CAM (2002) The importance of calcareous grasslands for butterflies in Europe. Biol Conserv 104(3):315-318.

Verble-Pearson RM, Gifford ME, Yanoviak SP (2015) Variation in thermal tolerance of North American ants. Journal of thermal biology 48:65-68.

Violle C, Reich PB, Pacala SW, Enquist BJ, Kattge J (2014) The emergence and promise of functional biogeography. PNAS 111(38):13690-13696. https://doi.org/10.1073/pnas.1415442111

Wang Y, Naumann U, Eddelbuettel D, et al (2020) mvabund: Statistical Methods for Analysing Multivariate Abundance Data. Version 4.1.6URL https://CRAN.R-project.org/package=mvabund

Weiss N, Zucchi H, Hochkirch A (2013) The effects of grassland management and aspect on Orthoptera diversity and abundance: site conditions are as important as management. Biodivers Conserv 22(10):2167-2178.

Peer] reviewing PDF | (2021:07:63673:1:0:NEW 11 Oct 2021) 
542 Westoby M (1998) A leaf-height-seed (LHS) plant ecology strategy scheme. Plant Soil 199:213-227.

543 https://doi.org/10.1023/A:1004327224729

544 Wiescher PT, Pearce-Duvet JM, Feener DH (2012) Assembling an ant community: species functional traits reflect 545 environmental filtering. Oecologia 169(4):1063-1074.

546 Wilkie KTR, Mertl AL, Traniello JFA (2010) Species diversity and distribution patterns of the ants of Amazonian 547 Ecuador. PLOS ONE 5(10): 10.1371/annotation/832d6104-4f9f-42eb-88a5-b2b1fc4480ca.

548 Wills BD, Landis DA (2018) The role of ants in north temperate grasslands: a review. Oecologia 186(2):323-338.

549 Wilson JB, Peet RK, Dengler J, Pärtel M (2012) Plant species richness: the world records. J Veg Sci 23:796-802. $550 \quad$ https://doi.org/10.1111/j.1654-1103.2012.01400.x

551 Wong MK, Guénard B, Lewis OT (2019) Trait-based ecology of terrestrial arthropods. Biological Reviews 552 94(3):999-1022.

553 Wright IJ, Reich PB, Westoby M, et al (2004) The worldwide leaf economics spectrum. Nature 428:821-827.

554 https://doi.org/10.1038/nature02403

555 Yates ML, Andrew NR, Binns M, Gibb H (2014) Morphological traits: predictable responses to macrohabitats across a $300 \mathrm{~km}$ scale. PeerJ 2:e271.

Zulka KP, Abensperg-Traun M, Milasowszky N, et al (2014) Species richness in dry grassland patches of eastern Austria: A multi-taxon study on the role of local, landscape and habitat quality variables. Agric Ecosyst Environ 182:25-36. https://doi.org/10.1016/j.agee.2013.11.016 
560 Figure 1. Map of the study area in Monti della Calvana (Italy) and its division into two ecosites.

561

562

563

564

565

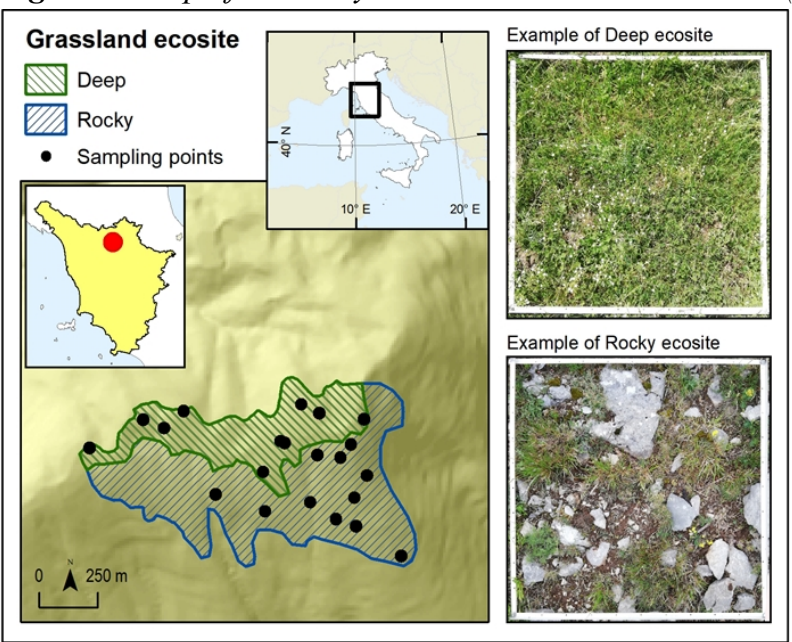

Figure 2. Variation of environmental variables (scale in $\mathrm{cm}$ for soil depth, microrelief and vegetation height, and \% for herb, and litter coverages) and plant ecological strategies between the two ecosites. Litter cover and $R$ strategy are log-transformed.
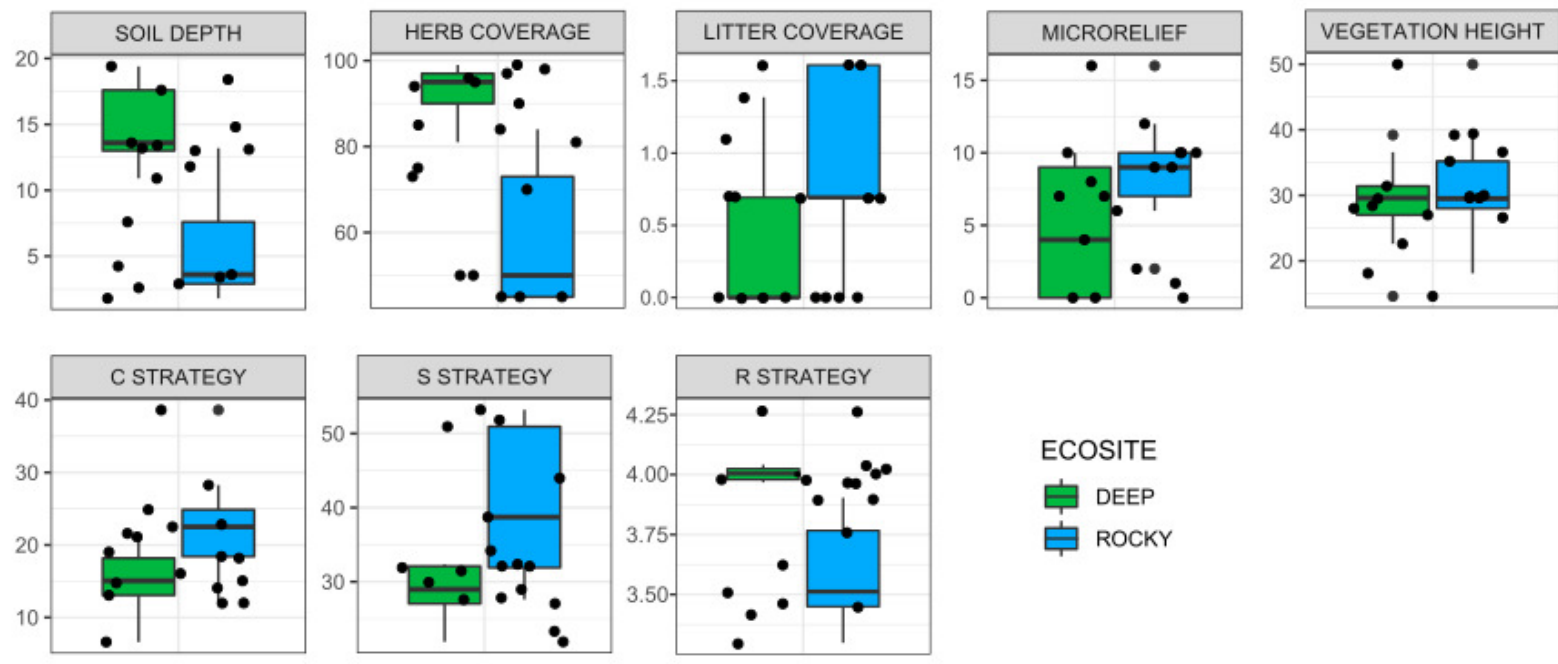

\section{ECOSITE}

官 DEEP

岁 ROCKY

566

567

568

Figure 3. Ecological strategies displayed in a ternary diagram using CSR values. 


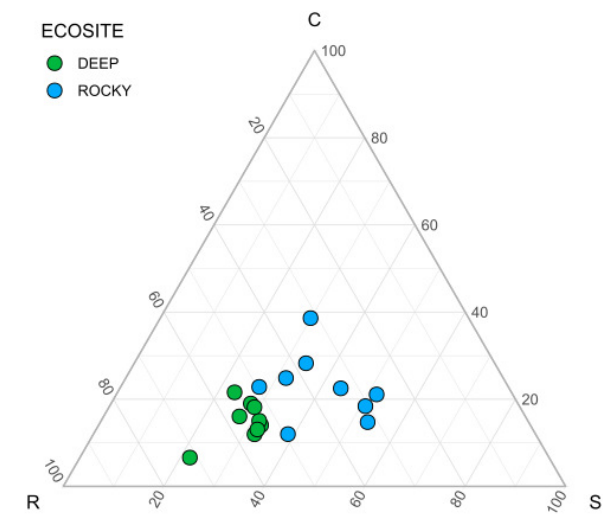

571 Figure 4. Community ordinations resulted by $n M D S$, according to plant (A) and ant (B) species and with respective 572 functional traits fitted onto ordinations. Green points correspond to plots from Deep ecosite, while blue points 573 represent those from Rocky ecosite. Abbreviation: $L A=$ leaf area, $S L A=$ specific leaf area, $S M=$ seed mass, $H=$ 574 plant height, $L D M C=$ leaf dry matter content, $W L=$ Weber's length, $H L=$ head length, $R L L=$ relative leg length, 575 Sugar Diet $=$ sugar-based diet, Seed Diet $=$ seed-based diet, Subordinate $=$ subordinate behaviour, Dominant $=$ 576 dominant behaviour.
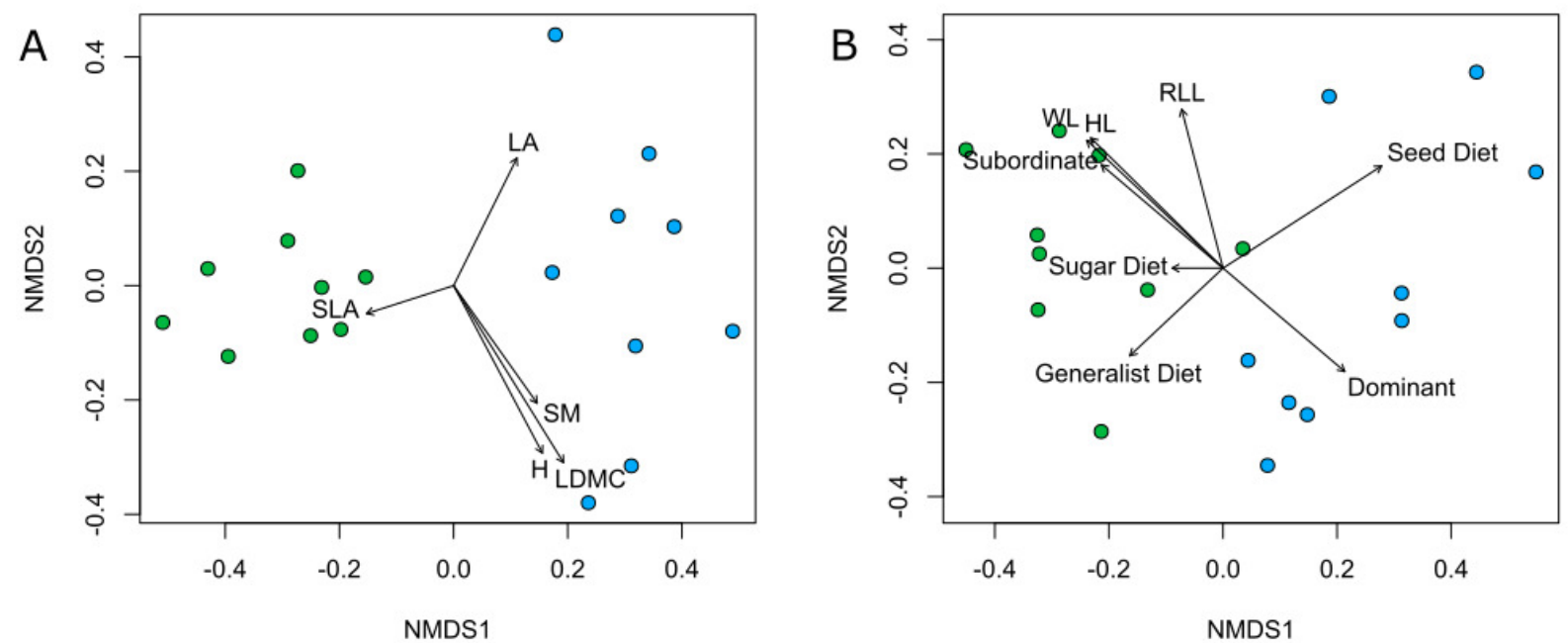

577

579 Figure 5. Relationships between environmental variables, ant species and ant traits assessed through fourth-corner analysis. On $y$ axis are reported ant functional traits, while on $x$ axis are reported environmental variables. Colors correspond to interaction coefficients (positive and negative) as reported in the bar on the right. 


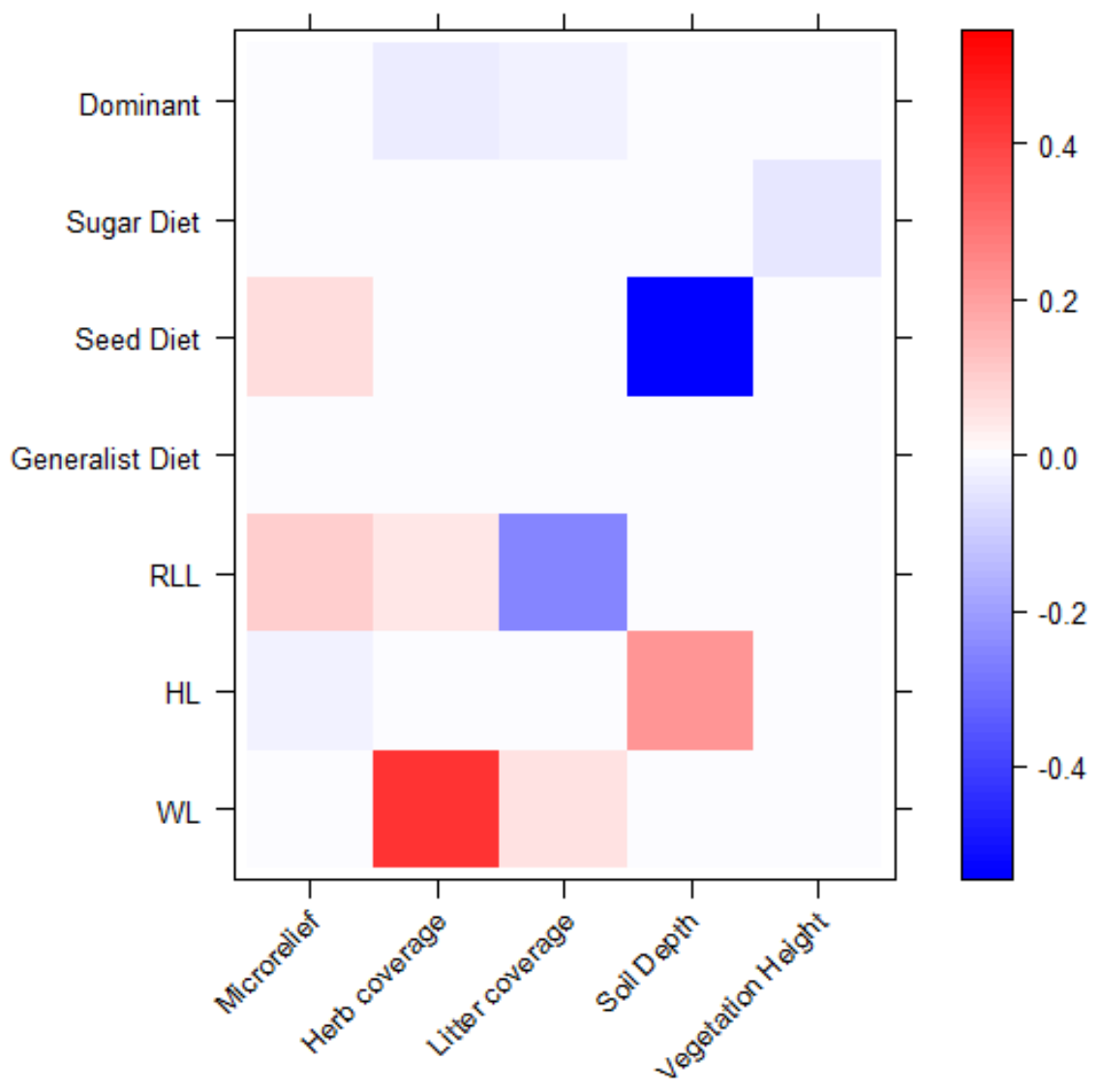

583

584 Table 1. ANOVA statistics on differences between the two ecosites. * denotes results of Welch ANOVA.

\begin{tabular}{|l|l|l|l|l|}
\hline \multicolumn{2}{|l|}{} & Df & F value & P value \\
\hline Environmental variables & Microrelief & 1 & 4.78 & 0.044 \\
\cline { 2 - 5 } & Herb coverage (\%)* & 1 & 35.06 & $<0.001$ \\
\cline { 2 - 6 } & Litter coverage (\%) & 1 & 3.02 & 0.101 \\
\cline { 2 - 6 } & Soil depth & 1 & 24.83 & $<0.001$ \\
\cline { 2 - 6 } & Vegetation height & 1 & 0.51 & 0.485 \\
\cline { 2 - 5 } & & 1 & 6.35 & 0.023 \\
\hline \multirow{5}{*}{ Ecological strategies } & C strategy & 10.6. & 0.005 \\
\hline & S strategy & & & \\
\hline & & & & \\
\hline
\end{tabular}


585

\begin{tabular}{|l|l|l|l|l|}
\hline & R strategy* & 1 & 30.16 & $<0.001$ \\
\hline
\end{tabular}

586 Table 2. Results of PERMANOVAs tested on plant and ant community compositions (nMDS).

\begin{tabular}{|l|l|l|l|l|}
\hline Community & Sum Sq & F value & $\mathrm{R}^{2}$ & $\mathrm{P}$ value \\
\hline Plant species & 1.760 & 9.651 & 0.376 & $<0.001$ \\
\hline Ant species & 1.533 & 9.800 & 0.38 & $<0.001$ \\
\hline
\end{tabular}

588 Table 3. Results of tests evaluating magnitude and directions of functional traits onto plant and ant species 589 compositions.

\begin{tabular}{|c|c|c|c|c|c|}
\hline \multicolumn{2}{|c|}{ Functional trait } & \multirow{2}{*}{$\begin{array}{l}\text { NMDS1 } \\
0.445\end{array}$} & \multirow{2}{*}{$\begin{array}{l}\text { NMDS2 } \\
0.895\end{array}$} & \multirow{2}{*}{$\begin{array}{l}\mathrm{R}^{2} \\
0.240\end{array}$} & \multirow{2}{*}{$\frac{P \text { value }}{0.130}$} \\
\hline Plant & LA & & & & \\
\hline & LDMC & 0.528 & -0.849 & 0.514 & 0.005 \\
\hline & SLA & -0.952 & -0.305 & 0.099 & 0.464 \\
\hline & $\mathrm{H}$ & 0.469 & -0.883 & 0.425 & 0.014 \\
\hline & SM & 10.579 & -0.815 & 0.246 & 0.122 \\
\hline \multirow[t]{8}{*}{ Ant } & WL & -0.713 & 0.701 & 0.792 & $<0.001$ \\
\hline & HL & -0.730 & 0.684 & 0.803 & $<0.001$ \\
\hline & RLL & -0.252 & 0.968 & 0.619 & 0.001 \\
\hline & Generalist diet & --0.729 & -0.684 & 0.376 & 0.026 \\
\hline & Seed diet & 0.841 & 0.541 & 0.819 & $<0.001$ \\
\hline & Sugar diet & -1.000 & 0.001 & 0.059 & 0.636 \\
\hline & Subordinate behaviour & -0.763 & 0.647 & 0.586 & 0.002 \\
\hline & Dominant behaviour & 0.763 & -0.647 & 0.586 & 0.002 \\
\hline
\end{tabular}


591 Table 4. Relationships among environment, vegetation and ant communities considering species and functional traits.

592 In both cases, correlation values above the diagonal correspond to simple Mantel tests, while correlation values below

593 the diagonal resulted from partial Mantel tests. In brackets are reported P values and significant correlations are in

594 bold. Following Frenette-Dussault et al. (2013) we considered as significance threshold $\alpha=0.10$.

\begin{tabular}{|c|c|c|c|}
\hline \multicolumn{4}{|l|}{ Taxonomic } \\
\hline & Environment & Vegetation & Ant \\
\hline Environment & & $0.75(<0.001)$ & $0.561(<0.001)$ \\
\hline Vegetation & $0.67(<0.001)$ & & $0.461(<0.001)$ \\
\hline Ant & $0.366(<0.001)$ & $0.074(0.227)$ & \\
\hline \multicolumn{4}{|l|}{ Functional } \\
\hline & Environment & Vegetation & Ant \\
\hline Environment & & $0.104(0.074)$ & $0.576(<0.001)$ \\
\hline Vegetation & $0.133(0.048)$ & & $-0.009(0.510)$ \\
\hline Ant & $0.581(<0.001)$ & $-0.084(0.772)$ & \\
\hline
\end{tabular}

595 


\section{Table $\mathbf{1}$ (on next page)}

ANOVA statistics on differences between the two ecosites.

ANOVA statistics on differences between the two ecosites. * denotes results of Welch ANOVA. 
1 Table 1. ANOVA statistics on differences between the two ecosites. * denotes results of Welch ANOVA.

\begin{tabular}{|l|l|l|l|l|}
\hline \multicolumn{2}{|l|}{} & Df & F value & P value \\
\hline Environmental variables & Microrelief & 1 & 4.78 & 0.044 \\
\cline { 2 - 6 } & Herb coverage (\%)* & 1 & 35.06 & $<0.001$ \\
\cline { 2 - 6 } & Litter coverage (\%) & 1 & 3.02 & 0.101 \\
\cline { 2 - 6 } & Soil depth & 1 & 24.83 & $<0.001$ \\
\cline { 2 - 6 } & Vegetation height & 1 & 0.51 & 0.485 \\
\hline \multirow{5}{*}{ Ecological strategies } & C strategy & 1 & 6.35 & 0.023 \\
\hline & & 1 & 10.6 & 0.005 \\
\hline & S strategy & 10.16 & $<0.001$ \\
\hline & & & & \\
\hline & R strategy* & 1 & & \\
\hline & & & & \\
\hline
\end{tabular}

2 


\section{Table 2 (on next page)}

Plant and ant community composition.

Results of PERMANOVAs tested on plant and ant community compositions (nMDS). 
1 Table 2. Results of PERMANOVAs tested on plant and ant community compositions (nMDS).

\begin{tabular}{|l|l|l|l|l|}
\hline Community & Sum Sq & F value & $\mathrm{R}^{2}$ & P value \\
\hline Plant species & 1.760 & 9.651 & 0.376 & $<0.001$ \\
\hline Ant species & 1.533 & 9.800 & 0.38 & $<0.001$ \\
\hline
\end{tabular}

2 


\section{Table 3(on next page)}

Functional traits in plant and ant communities.

Results of tests evaluating magnitude and directions of functional traits onto plant and ant species compositions. 
1 Table 3. Results of tests evaluating magnitude and directions of functional traits onto plant and ant species 2 compositions.

\begin{tabular}{|c|c|c|c|c|c|}
\hline \multicolumn{2}{|c|}{ Functional trait } & \multirow{2}{*}{$\begin{array}{l}\text { NMDS1 } \\
0.445\end{array}$} & \multirow{2}{*}{$\begin{array}{l}\text { NMDS2 } \\
0.895\end{array}$} & \multirow{2}{*}{$\begin{array}{l}\mathrm{R}^{2} \\
0.240\end{array}$} & \multirow{2}{*}{$\begin{array}{l}\text { P value } \\
0.130\end{array}$} \\
\hline Plant & LA & & & & \\
\hline & LDMC & 0.528 & -0.849 & 0.514 & 0.005 \\
\hline & SLA & -0.952 & -0.305 & 0.099 & 0.464 \\
\hline & $\mathrm{H}$ & 0.469 & -0.883 & 0.425 & 0.014 \\
\hline & SM & 10.579 & -0.815 & 0.246 & 0.122 \\
\hline \multirow[t]{8}{*}{ Ant } & WL & -0.713 & 0.701 & 0.792 & $<0.001$ \\
\hline & HL & -0.730 & 0.684 & 0.803 & $<0.001$ \\
\hline & RLL & -0.252 & 0.968 & 0.619 & 0.001 \\
\hline & Generalist diet & --0.729 & -0.684 & 0.376 & 0.026 \\
\hline & Seed diet & 0.841 & 0.541 & 0.819 & $<0.001$ \\
\hline & Sugar diet & -1.000 & 0.001 & 0.059 & 0.636 \\
\hline & Subordinate behaviour & -0.763 & 0.647 & 0.586 & 0.002 \\
\hline & Dominant behaviour & 0.763 & -0.647 & 0.586 & 0.002 \\
\hline
\end{tabular}

3 


\section{Table 4 (on next page)}

Relationships between environment and plant and ant communities.

Relationships among environment, vegetation and ant communities considering species and functional traits. In both cases, correlation values above the diagonal correspond to simple Mantel tests, while correlation values below the diagonal resulted from partial Mantel tests. In brackets are reported $\mathrm{P}$ values and significant correlations are in bold. Following FrenetteDussault, Shipley $\&$ Hingrat (2013) we considered as significance threshold $\alpha=0.10$. 
1 Table 4. Relationships among environment, vegetation and ant communities considering species and functional traits.

2 In both cases, correlation values above the diagonal correspond to simple Mantel tests, while correlation values below

3 the diagonal resulted from partial Mantel tests. In brackets are reported P values and significant correlations are in

4 bold. Following Frenette-Dussault et al. (2013) we considered as significance threshold $\alpha=0.10$.

\begin{tabular}{|c|c|c|c|}
\hline \multicolumn{4}{|l|}{ Taxonomic } \\
\hline & Environment & Vegetation & Ant \\
\hline Environment & & $0.75(<0.001)$ & $0.561(<0.001)$ \\
\hline Vegetation & $0.67(<0.001)$ & & $0.461(<0.001)$ \\
\hline Ant & $0.366(<0.001)$ & $0.074(0.227)$ & \\
\hline \multicolumn{4}{|l|}{ Functional } \\
\hline & Environment & Vegetation & Ant \\
\hline Environment & & $0.104(0.074)$ & $0.576(<0.001)$ \\
\hline Vegetation & $0.133(0.048)$ & & $-0.009(0.510)$ \\
\hline Ant & $0.581(<0.001)$ & $-0.084(0.772)$ & \\
\hline
\end{tabular}

5 
Figure 1

Map of the study area

Map of the study area in Monti della Calvana (Italy) and its division into two ecosites.

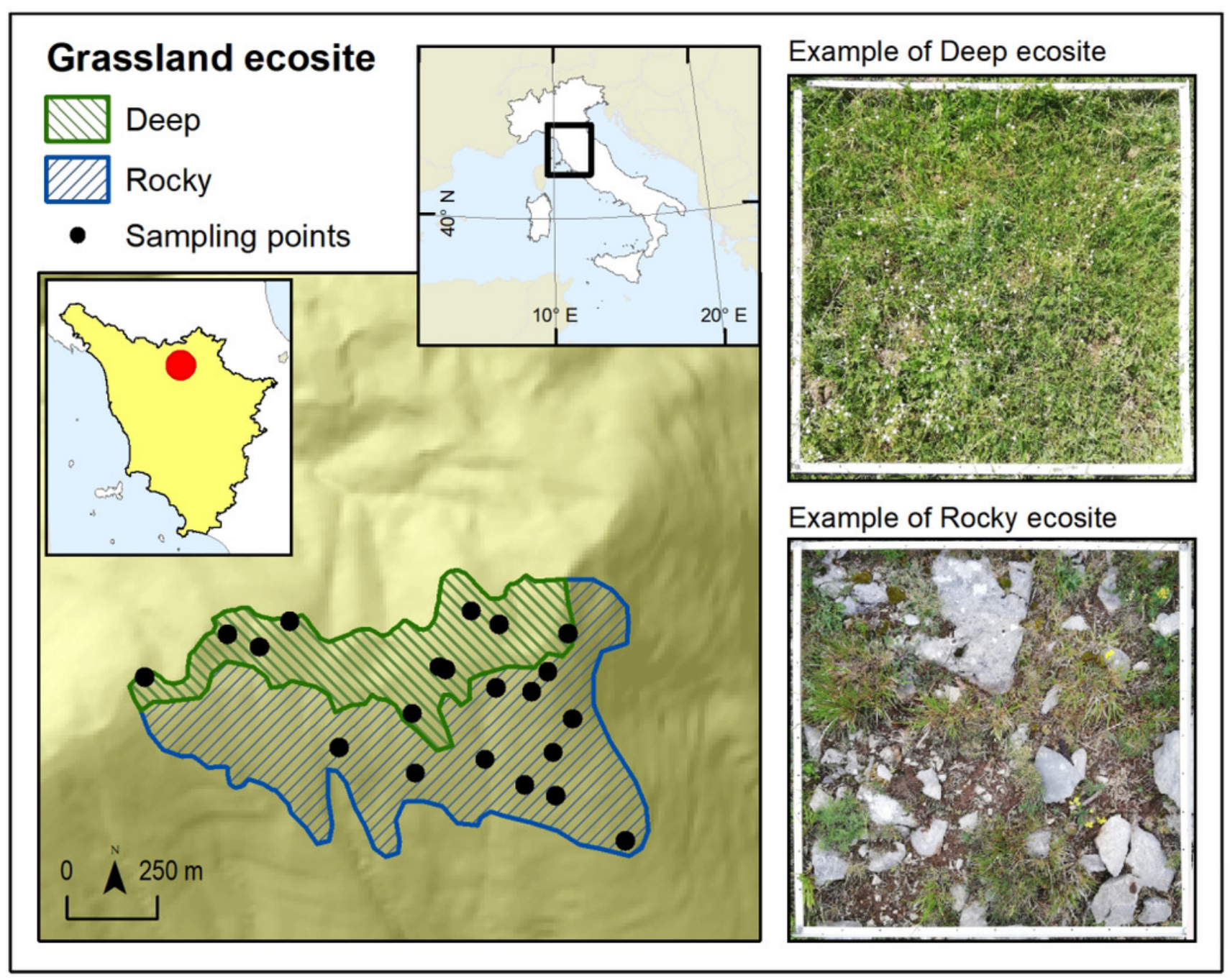


Figure 2

Variation of environmental variables and plant ecological strategies between the two ecosites.

Variation of environmental variables (scale in $\mathrm{cm}$ for soil depth, microrelief and vegetation height, and \% for herb, and litter coverages) and plant ecological strategies between the two ecosites. Litter cover and $R$ strategy are log-transformed.
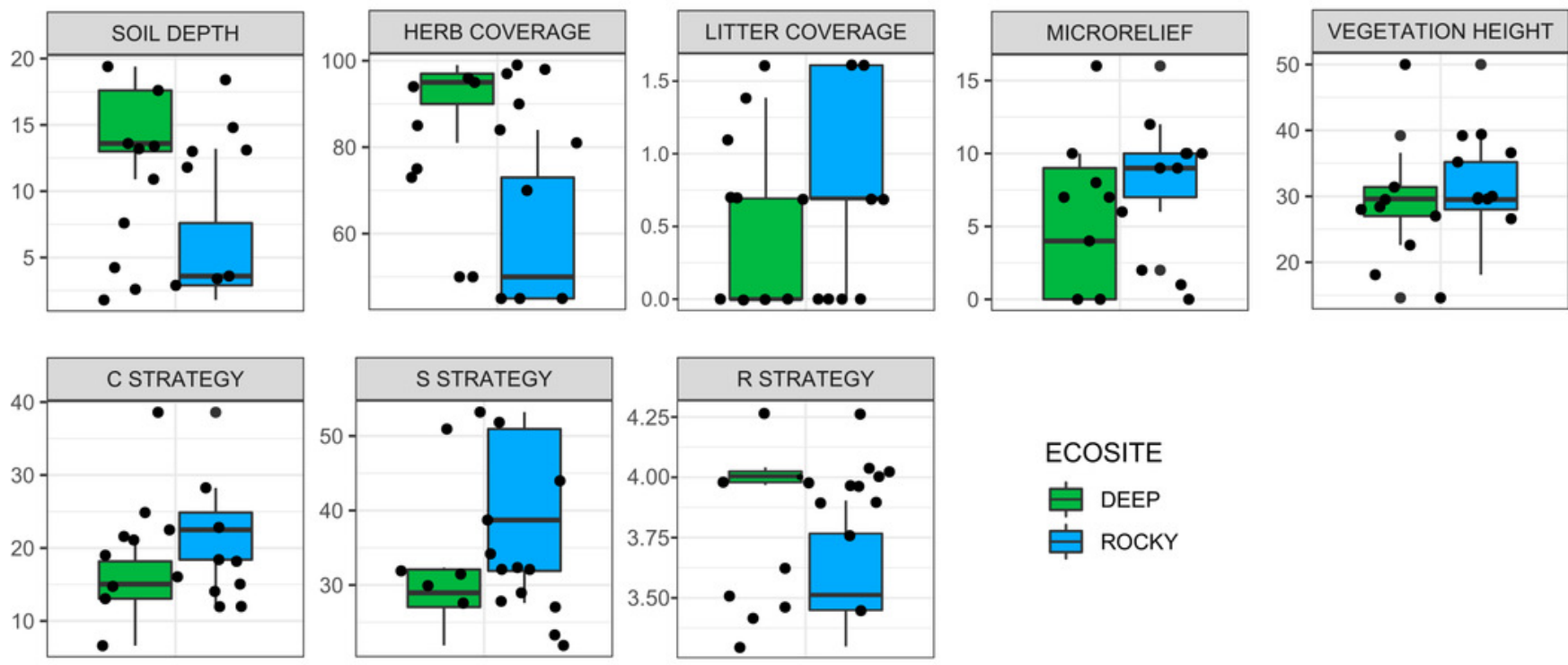

ECOSITE

官 DEEP

官 ROCKY 
Figure 3

Ecological strategies of communities using CSR values.

Ecological strategies displayed in a ternary diagram using CSR values.

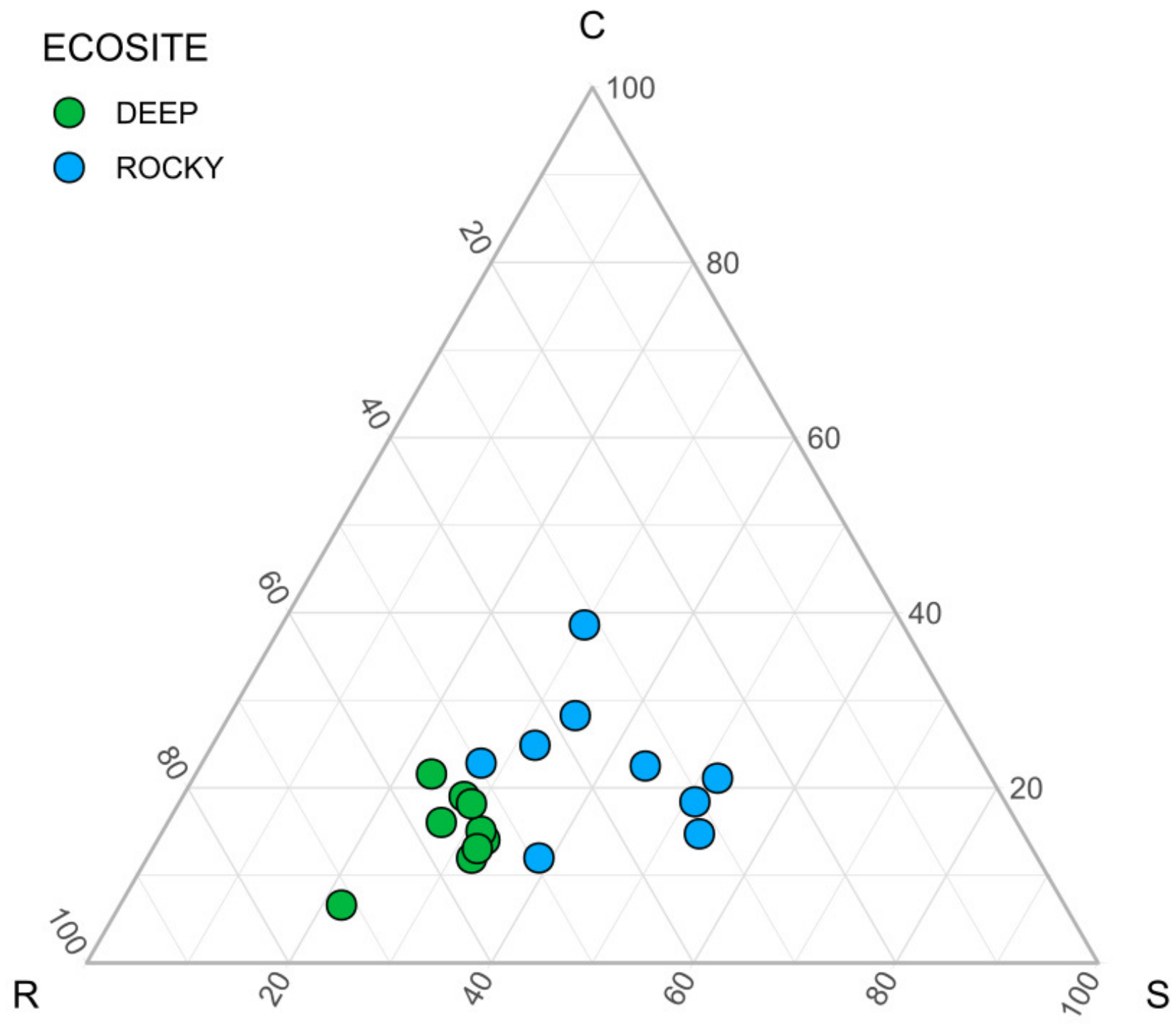


Figure 4

Community plant and ant ordinations resulted by nMDS.

Community ordinations resulted by nMDS, according to plant (A) and ant (B) species and with respective functional traits fitted onto ordinations. Green points correspond to plots from Deep ecosite, while blue points represent those from Rocky ecosite. Abbreviation: $L A=$ leaf area, $S L A=$ specific leaf area, $S M=$ seed mass, $H=$ plant height, $L D M C=$ leaf dry matter content, $W L=$ Weber's length, $H L=$ head length, $R L L=$ relative leg length, Sugar Diet $=$ sugar-based diet, Seed Diet $=$ seed-based diet, Subordinate $=$ subordinate behaviour, Dominant $=$ dominant behaviour.
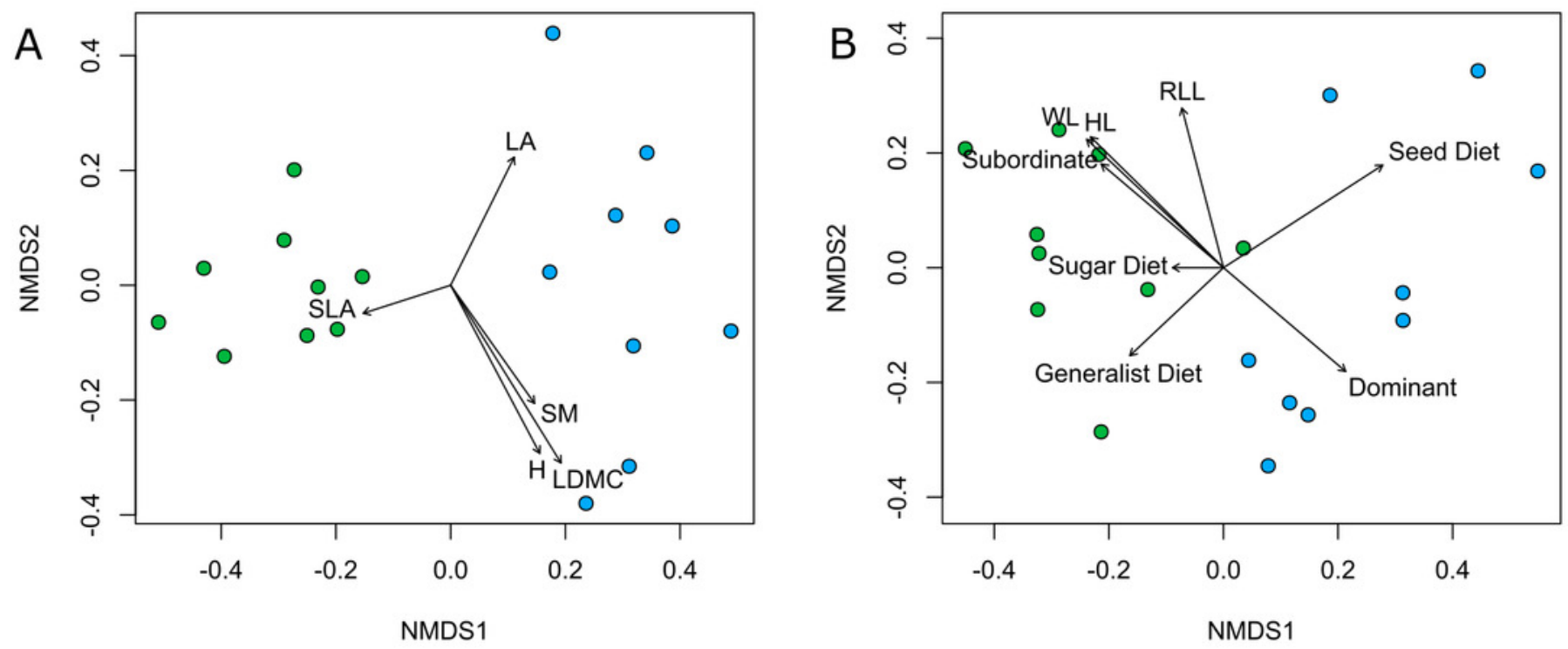


\section{Figure 5}

Relationships between environmental variables, ant species and ant traits assessed through fourth-corner analysis.

Relationships between environmental variables, ant species and ant traits assessed through fourth-corner analysis. On y axis are reported ant functional traits, while on $x$ axis are reported environmental variables. Colors correspond to interaction coefficients (positive and negative) as reported in the bar on the right. 


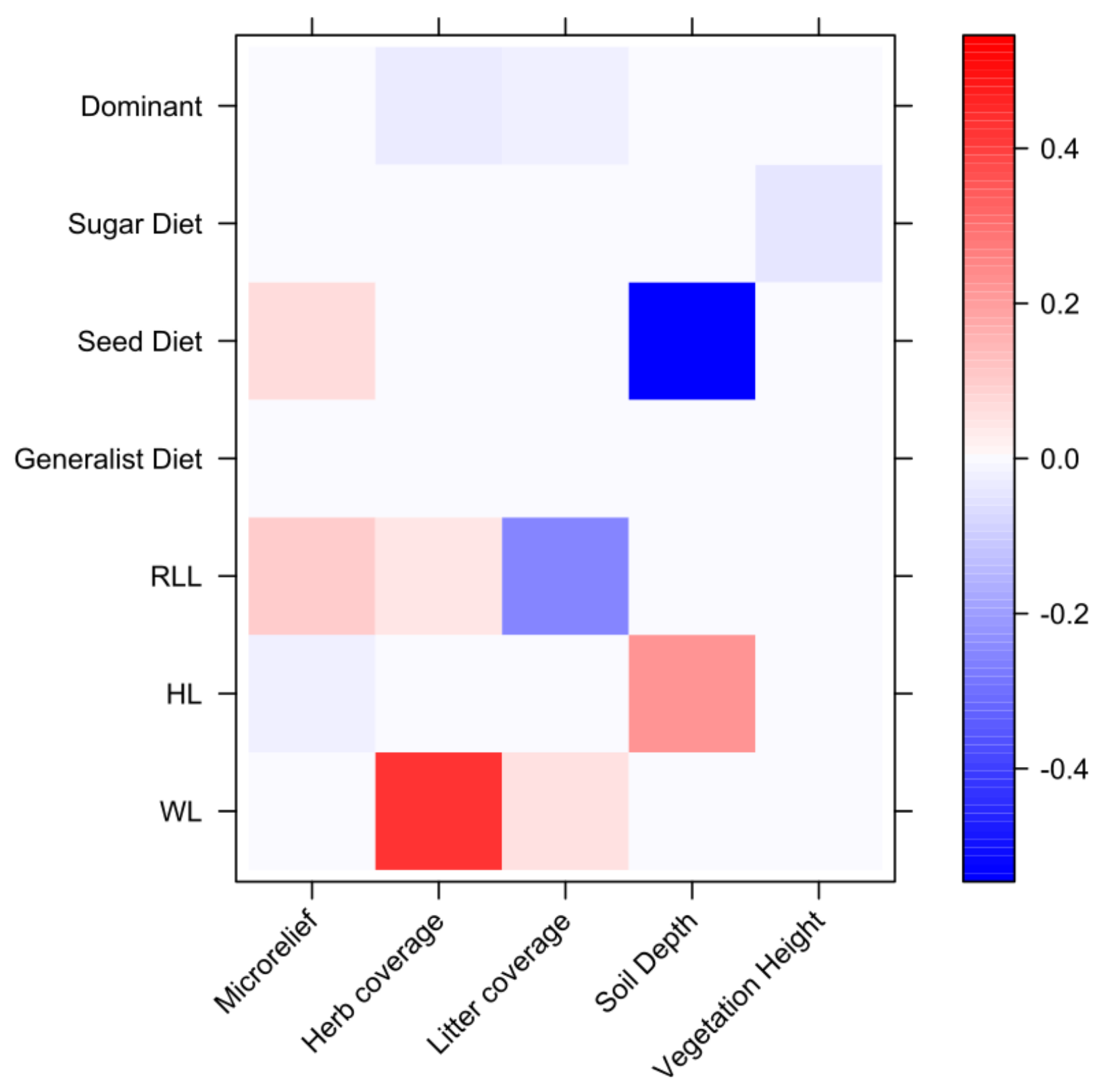

